\title{
Lung volume indices predict morbidity in smokers with preserved spirometry
}

\author{
Siyang Zeng, ${ }^{1,2}$ Andrea Tham, ${ }^{1,3}$ Bruce Bos, ${ }^{1,4}$ Joan Jin, ${ }^{1,5}$ Brian Giang, ${ }^{1,2}$ \\ Mehrdad Arjomandi, 1
}

- Additional material is published online only. To view please visit the journal online (http://dx.doi.org/10.1136/ thoraxjnl-2018-211881).

${ }^{1}$ Medical Section, San Francisco Veterans Affairs Medical Center, San Francisco, California, USA ${ }^{2}$ Department of Medicine, University of California, San Francisco, California, USA ${ }^{3}$ School of Medicine, University of Southern California, LoS Angeles, USA

${ }^{4}$ School of Medicine, Radboud University Medical Center, Nijmegen, Gelderland, The Netherlands

${ }^{5}$ School of Pharmacy, University of Illinois at Chicago, Chicago, Illinois, USA

\section{Correspondence to}

Dr Mehrdad Arjomandi, Division of Pulmonary, Critical Care, Allergy and Immunology, and Sleep Medicine, University of California, San Francisco Veterans Affairs Medical Center, San Francisco, CA 94121, USA mehrdad.arjomandi@ucsf.edu

SZ and AT contributed equally.

Received 30 March 2018 Revised 19 June 2018 Accepted 25 June 2018 Published Online First 20 July 2018

\begin{abstract}
Background Abnormal lung volumes that reflect air trapping are common in COPD. However, their significance in smokers with preserved spirometry (normal FEV to FVC ratio) is unclear.
\end{abstract}

Methods Using the Veterans Administration Informatics and Computing Infrastructure database, we identified 7479 patients at risk for COPD (ever smokers $>40$ years of age without restrictive lung disease) who had preserved spirometry and concomitant lung volume measurements, and examined their subsequent health records for clinical diagnoses of COPD, healthcare utilisation, follow-up spirometry and mortality.

Results Air trapping was prevalent, with $31 \%$ of patients having residual volume to total lung capacity ratio (RV:TLC) greater than the upper limit of normal (ULN). RV:TLC varied widely from $14 \%$ to $77 \%$ (51\% to $204 \%$ of predicted) across the normal ranges of $\mathrm{FEV}_{1}$ :FVC and $\mathrm{FEV}_{1}$. Patients with RV:TLC greater than the ULN were more likely to receive subsequent clinical diagnoses of COPD (HR $(95 \% \mathrm{Cl})=1.55(1.42$ to 1.70$), p<0.001)$ and had higher all-cause mortality $(\mathrm{HR}(95 \% \mathrm{Cl})=1.41$ (1.29 to 1.54), $\mathrm{p}<0.001)$. They had higher rates of respiratory medication prescriptions and hospital and intensive care unit admissions. Other air trapping and static hyperinflation indices showed similar associations with health outcomes. Additionally, high-normal RV:TLC was associated with intermediate adverse health outcomes compared with low-normal and abnormal RV:TLC. Abnormal RV:TLC predicted higher likelihood of progression to spirometric COPD (OR $(95 \% \mathrm{Cl})=1.30$ (1.03 to 1.65$), \mathrm{p}=0.027)$.

Conclusion In this study of the Veterans Affairs electronic health records, air trapping was common in smokers with preserved spirometry and predicted adverse respiratory outcomes and progression to overt COPD.

\section{INTRODUCTION}

The Global Initiative on Obstructive Lung Disease (GOLD) defines COPD by an absolute reduction in $\mathrm{FEV}_{1}$ to $\mathrm{FVC}$ ratio of $<0.70$ after albuterol administration (stage 1), with higher stages of COPD defined by a concomitant reduction in $\mathrm{FEV}_{1}$ as a per cent predicted. ${ }^{1}$ Other criteria emphasise a lower-limit-of-predicted normal (LLN) approach rather than a standard fixed cut-point in $\mathrm{FEV}_{1}: \mathrm{FVC}$, but nonetheless rely on the same basic metrics of spirometry. ${ }^{2}$ Many current and former smokers without GOLD-defined (or LLN-defined) COPD have similar acute and chronic respiratory symptoms as those with COPD and may proceed

\section{Key messages}

What is the key question?

- Could lung volumes predict progression to overt COPD in smokers without airflow obstruction?

What is the bottom line?

- This retrospective analysis of the US Veterans Affairs electronic health records showed that abnormal lung volumes representing air trapping are common in smokers without COPD and are associated with higher healthcare utilisation, death and decline in lung function.

Why read on?

- Understanding the predictors of morbidity and disease progression in smokers without COPD is extremely important for prognostication and early intervention.

to develop overt disease. ${ }^{4-7}$ Thus, the ability to identify the smokers with preserved spirometry (GOLD-defined or LLN-defined) who are at risk for the development of respiratory problems and disease progression is of great interest for prognostication and intervention purposes.

Air trapping, defined as abnormal increase in volume of air remaining in the lungs at the end of exhalation, is a manifestation of obstructive lung diseases including COPD. Air trapping in people with COPD is associated with increased dyspnoea, reduced functional capacity and higher mortality. ${ }^{89}$ However, its clinical significance in smokers without COPD (normal $\mathrm{FEV}_{1}: \mathrm{FVC}$ and $\mathrm{FEV}_{1}$ ) is unknown. In fact, abnormal lung volumes suggestive of air trapping are routinely ignored in the interpretation of lung function when spirometry is preserved.

In this study, we hypothesised that in patients at risk for COPD due to smoking but with preserved spirometry, those with air trapping (and static hyperinflation) as measured by residual volume (RV), functional residual capacity (FRC), inspiratory capacity (IC) and their ratios to total lung capacity (TLC) have increased respiratory morbidity and mortality. To test this, we identified 7479 patients from the Veterans Administration Informatics and Computing Infrastructure (VINCI) database at risk for COPD due to smoking who ever had a pulmonary function test (PFT) with concomitant lung volume measurements that showed preserved spirometry (defined by $\mathrm{FEV}_{1}: \mathrm{FVC}$ and $\mathrm{FEV}_{1} \geq \mathrm{LLN}$ ). We then reviewed their subsequent electronic health records 
(EHR) and determined whether patients with air trapping were more likely to have adverse health outcomes compared with those without air trapping.

\section{METHODS}

\section{Study design}

This was a retrospective study of EHR available from the nationwide Veterans Health Administration (VHA) VINCI database with patients at risk for COPD (current or former smokers $>40$ years of age) who ever had a full PFT between 1985 and 2017. Medical records of eligible patients were interrogated to quantify the frequency of acute and chronic respiratory outcomes and mortality subsequent to their very first PFT that included prealbuterol and postalbuterol administration spirometry and lung volume measurement by plethysmography. The latest postbronchodilator spirometry that was available in their EHR was also examined. Mortality data were extracted from documented death notes, and patients were considered to be alive up to the date of their last medical encounter, after which they were considered as lost to follow-up. The utility of lung volume indices from the first PFT to predict the subsequent occurrence of the above outcomes was assessed in those with preserved spirometry.

The University of California San Francisco Institutional Review Board and the Veterans Health Administration Research and Development Committee approved this study. Detailed inclusion and exclusion algorithm and the International Classification of Diseases (ICD)-9 and ICD-10 diagnosis codes used are available in the online supplementary appendix.

\section{Study population}

From 1985 to 2017,127940 patients from the VHA were documented to have received full PFT including postbronchodilator spirometry and lung volume measurements by plethysmography. Our study aimed to focus on patients at risk for COPD as defined by those who were $>40$ years of age and had diagnosis of tobacco use at the time of their full PFT. Smoking status was assigned by documented diagnosis of ICD-9 or ICD-10 codes or diagnosis of smoking on PFT report. Accordingly, 52668 patients who were not considered to be at risk for COPD were excluded. Patients were further excluded if they had evidence of restrictive lung disease on PFT as determined by TLC $\leq 80 \%$ or $<$ LLN, diagnoses of interstitial lung diseases, or allergic lung diseases (except for asthma). Patients with a diagnosis of asthma who were considered to be at risk for COPD were not excluded to avoid exclusion of those with overlap disease. A further 35286 patients were excluded who had abnormal spirometry $\left(\mathrm{FEV}_{1}: \mathrm{FVC}\right.$ or $\left.\mathrm{FEV}_{1}<\mathrm{LLN}\right)$. Overall, data were available from 7479 patients at risk for COPD but with preserved spirometry from 37 Veterans Affairs Medical Centers across the USA (figure 1). Data from other Veterans Affairs Medical Centers were not used due to lack of availability of coded PFT data that would be obtainable through VINCI.

\section{Statistical analysis}

\section{Data management}

Predicted values and ranges for PFT measurements were calculated using Crapo predicted formulas, ${ }^{10-12}$ except for FRC:TLC, IC and IC:TLC for which data from Quanjer et al and Francisco et al were used. ${ }^{213}$ Patients were categorised to have air trapping if they had abnormal RV:TLC (greater than the upper limit of normal (ULN)). Those with normal RV:TLC were further categorised into low-normal and high-normal groups relative to the median value of the distribution of normal RV:TLC.

\section{Outcomes}

Healthcare outcomes including clinical diagnoses, respiratory medication prescribed, outpatient office visits, emergency room (ER) visits, hospital admissions and intensive care unit (ICU) admissions with a COPD diagnosis and all-cause mortality
47,761 No Smoking History 4,907 Age $<40$

75,272 At Risk for COPD

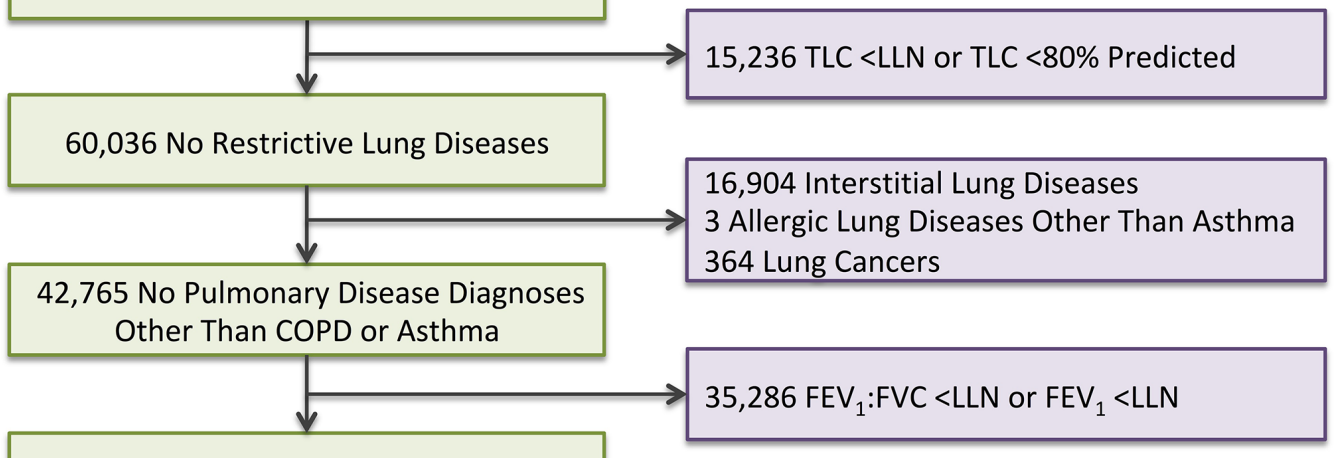

7,479 Preserved Spirometry

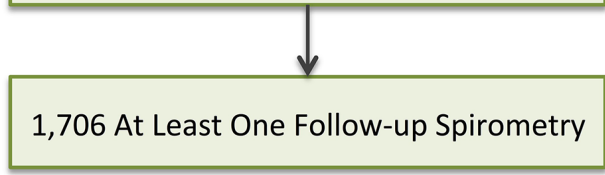

Figure 1 Subject flow. LLN, lower limit of normal; PFT, pulmonary function test; TLC, total lung capacity. 
were also acquired based on the ICD-9 and ICD-10 codes and prescription information along with the relevant dates as detailed in the online supplementary appendix.

\section{Analyses}

Distributions of patients' demographics and lung function were computed, and the differences between the groups of patients were examined using $\chi^{2}$ test, Wilcoxon-Mann-Whitney tests and Student's t-test for comparison of binary, ordinal and continuous variables, respectively. Correlations among airflow obstruction indices $\left(\mathrm{FEV}_{1}: \mathrm{FVC}\right.$ and $\left.\mathrm{FEV}_{1}\right)$ and air trapping (RV:TLC) were examined using Pearson's correlation test. To control for age, height and sex covariates when examining the absolute PFT values, partial and semipartial correlations were examined.

Cox proportional hazards regression models were used to analyse the association between air trapping and 'clinical diagnosis of COPD' and 'all-cause mortality'. The associations of air trapping with aggregated counts of 'respiratory medications', 'office visits', 'ER visits', 'hospital admissions' and 'ICU admissions' for each patient were analysed using Poisson regression modelling to examine the incident rate ratios of such events with consideration of follow-up time. Since the time from index PFT to last follow-up spirometry does not reflect the time at which the patient actually developed spirometric COPD, the association of air trapping with progression to COPD ('COPD on follow-up spirometry') was analysed using mixed effect logistic regression modelling, instead of Cox proportional hazard. To do this, time to follow-up spirometry was divided into quartiles and included in the model as the random effect variable. Similarly, mixed effect linear regression modelling was used for examining the associations of air trapping with changes in spirometric indices. All models included absolute values of lung function and were then adjusted internally for age, sex and height based on an a priori decision.

Sensitivity analyses were performed by excluding patients with specific characteristics that could act as confounders, including obesity, asthma, $\mathrm{FEV}_{1}$ reversibility, or FVC and maximum airflow at mid-lung volume $\left(\mathrm{FEF}_{25-75}\right)$ less than the LLN individually. To examine any possible medical centre effect, additional sensitivity analyses were also performed by adjusting for clusters in Cox proportional hazard models or including the centres as a random effect in other models.

Line graph comparisons were done in GraphPad Prism (V.7.0c; GraphPad Software, La Jolla, California, USA). Data management, figure generation and Cox proportional hazards regression plots were done using R (V.3.3.2; R Foundation for Statistical Computing, Vienna, Austria). Other data analyses were conducted in STATA V.14.1.

\section{RESULTS}

\section{Subject characteristics}

In this VINCI cohort of 7479 patients at risk for COPD but with preserved spirometry, RV:TLC in the earliest available PFT was above ULN in 30.8\%, while other measures of air trapping and static hyperinflation (FRC, FRC:TLC, IC and IC:TLC) were abnormal in a smaller fraction of patients $(<5 \%)$ (table 1 and online supplementary appendix). Patients with abnormal RV:TLC were slightly older, included a higher proportion of men, and in general had worse airflow and air trapping indices compared with their counterparts with normal RV:TLC.

\section{Relationship between lung volume and airflow indices}

To examine the distribution of air trapping across airflow indices, $\mathrm{FEV}_{1}: \mathrm{FVC}$ and $\mathrm{FEV}_{1}$ were stratified into $5 \%$ increments based on their predicted values and plotted against RV:TLC (figure 2). RV:TLC spanned from 14\% to 77\% (51\% to $204 \%$ of predicted) and varied widely at each increment of $\mathrm{FEV}_{1}: \mathrm{FVC}$ and $\mathrm{FEV}_{1}$, with ranges as high as $150 \%$ and $143 \%$ of predicted value, corresponding to coefficients of variation (SD to mean ratio) of $18.9 \%$ and $25.2 \%$, respectively.

\section{Association between lung volume indices and healthcare outcomes}

\section{Air trapping and healthcare outcomes}

The average follow-up time period available was $8.6 \pm 4.8$ years (median time of 8.2 years with IQR of 4.6-12.2 years and a total range of 1-24 years). During this follow-up period, those with abnormal RV:TLC among patients with preserved spirometry were more likely to receive COPD diagnoses (HR $(95 \% \mathrm{CI})=1.55(1.42$ to 1.70$), \mathrm{p}<0.001)$ and to have higher all-cause mortality (HR $(95 \% \mathrm{CI})=1.41$ (1.29 to 1.54$)$, $\mathrm{p}<0.001)$ compared with their normal RV:TLC counterparts (adjusted for covariates including years of follow-up) (table 2). They also had an increased rate of respiratory medication prescribed, and higher occurrence of outpatient office visits, ER visits, hospital admissions and ICU admissions with COPD diagnoses (table 2). Furthermore, patients with abnormal RV:TLC had reduced time to COPD-related illnesses and death from all causes compared with their counterparts with normal RV:TLC (figure 3). Similar findings were observed when FRC, FRC:TLC, IC or IC:TLC instead of RV:TLC were used in these analyses, with the exception of respiratory medication prescription numbers (online supplementary appendix).

\section{Air trapping and healthcare outcomes with inclusion of airflow} indices

Inclusion of airflow indices $\left(\mathrm{FEV}_{1}: \mathrm{FVC}, \mathrm{FEV}_{1}\right.$ and $\left.\mathrm{FEF}_{25-75}\right)$ in the multivariate analysis did not affect the observed association of air trapping, with either COPD diagnoses, respiratory medications, office visits, hospital admissions or mortality with $\mathrm{RV}$ :TLC on index PFT remaining an independent predictor for those outcomes (table 2).

\section{Normal RV:TLC and healthcare outcomes}

To further examine the relationship between gradient of lung volumes and health outcomes, we examined RV:TLC as a continuous variable and found it to have similar associations with health outcomes (table 2). For example, every 10\% increase in RV:TLC (absolute value) on index PFT resulted in $33 \%$ higher likelihood of receiving a COPD diagnosis, 31\% more COPD-related hospital admissions and 2\% higher likelihood of dying from any cause during the follow-up period. Furthermore, when we stratified patients with normal RV:TLC into high and low groups relative to the median RV:TLC, we found those with high-normal RV:TLC to have an overall increased occurrence of COPD-related adverse health outcomes compared with those with low-normal RV:TLC, but decreased occurrence compared with those with abnormal RV:TLC (figure 4).

\section{Association between lung volume indices and progression to spirometric COPD}

We looked to see if any of the patients had follow-up postbronchodilator spirometry after their index PFT and 
Table 1 Characteristics of all subjects

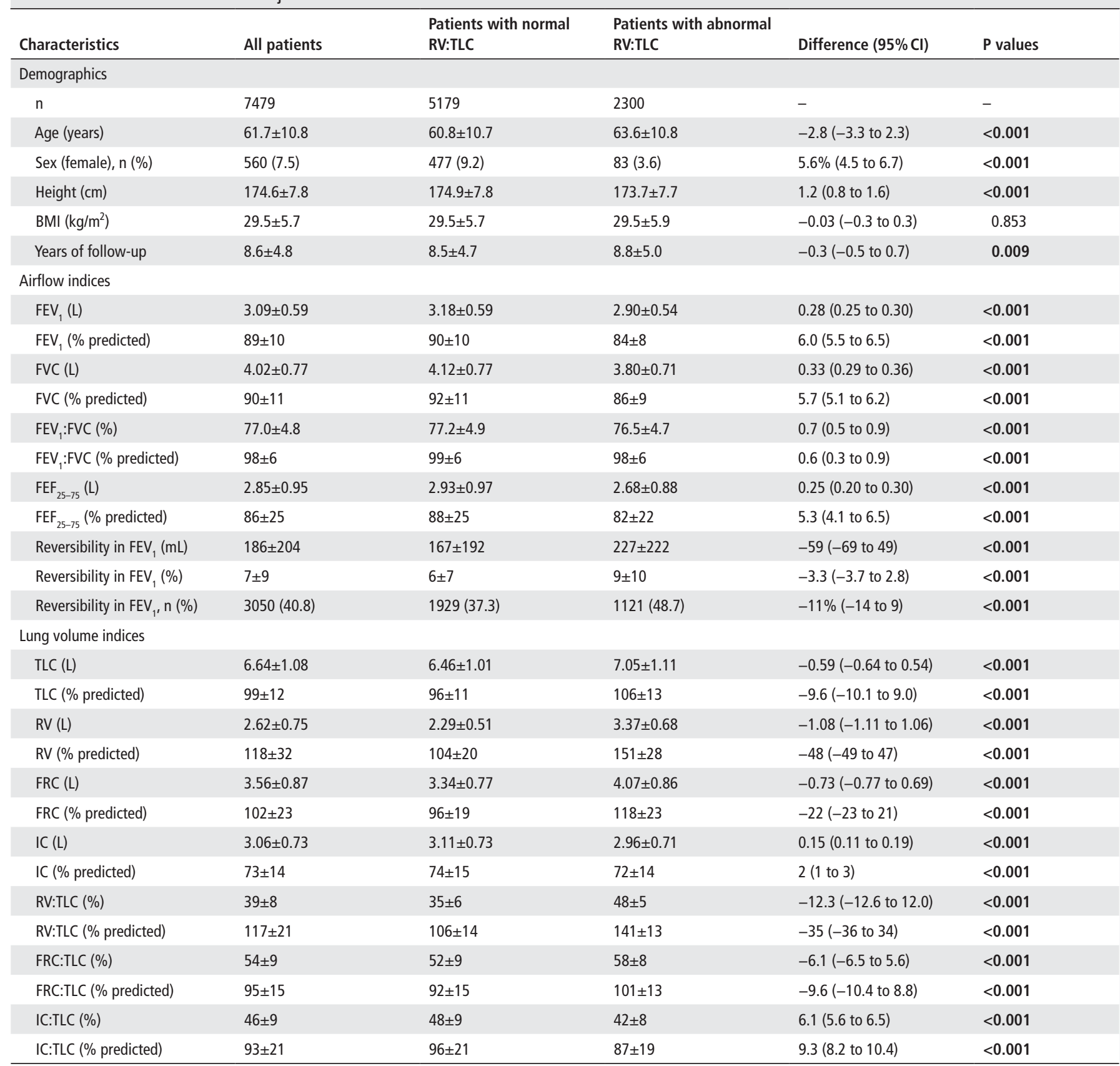

P-values for significant comparisons are shown in bold.

Demographics and lung function in patients with preserved spirometry. Patients were stratified according to abnormal and normal RV:TLC by the upper limit of normal. Data are presented as mean $\pm \mathrm{SD}$ or number of patients with positive value for the variable $(\mathrm{n})$ out of the total number of patients $(\mathrm{N})$ and percentage of patients $(\%)$ and difference $(95 \% \mathrm{Cl})$ with $\mathrm{p}$ value for unadjusted comparison between normal and abnormal RV:TLC. Reference equations: Measures of pulmonary function and \% predicted of normal values were calculated using Crapo predicted formulas (Crapo et al ${ }^{11} 12,1981$ and 1982), except for FRC:TLC, IC and IC:TLC. Quanjer predicted formulas were used for FRC:TLC and IC (Quanjer et $\mathrm{al}^{2}{ }^{2}$ 1993), and Francisco predicted formulas were used for IC:TLC (Francisco et al $^{13}$ 2009). Reversibility defined as $\geq 12 \%$ and $\geq 200 \mathrm{~mL}$ increase in FEV after bronchodilator administration.

$\mathrm{BMI}$, body mass index; $\mathrm{FEF}_{25-75}$, maximum airflow at mid-lung volume; FRC, functional residual capacity; IC, inspiratory capacity; RV, residual volume; TLC, total lung capacity.

examined the last such spirometry that was available in their records. We found 1706 patients (582 (34\%) with abnormal RV:TLC) to have such spirometry $4.1 \pm 3.1$ years after their index PFT (median time of 3.3 years with an IQR of 1.8-5.6 years) (table 3). The time interval between the index PFT and the follow-up spirometry was slightly longer in those with abnormal RV:TLC (difference of 0.8 years (95\% CI 0.5 to 1.1 years), $\mathrm{p}<0.001$ ). Patients with abnormal
RV:TLC were more likely to develop spirometric COPD (OR $(95 \% \mathrm{CI})=1.30(1.03$ to 1.65$), \mathrm{p}=0.027$; adjusted for years of follow-up).

In models that examined the change in spirometric indices in a continuous manner, the change in $\mathrm{FEV}_{1}$ was not different between those with abnormal RV:TLC compared with their normal counterparts $(\mathrm{p}=0.889)$ (figure 5$)$. However, those with abnormal RV:TLC had a significant increase in FVC $(p=0.041)$, 

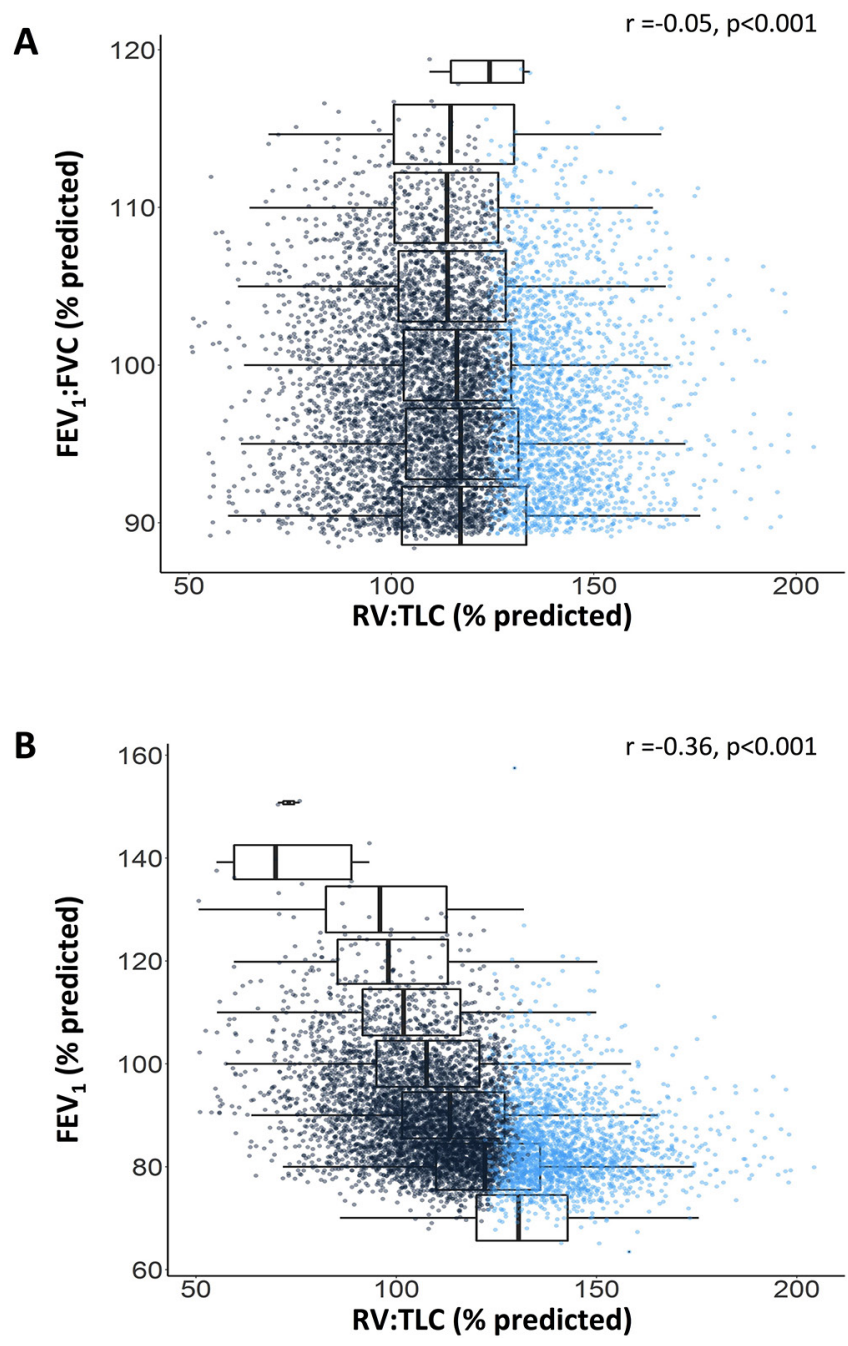

Figure 2 Association between RV:TLC and FEV $: F V C$ or FEV in the cohort. Relationship between RV:TLC (\% predicted) and FEV:FVC (\% predicted), or $\mathrm{FEV}_{1}$ (\% predicted). Boxplot distribution of RV:TLC $\%$ predicted by $5 \%$ increments in $\mathrm{FEV}_{1}:$ FVC $\%$ predicted $(\mathrm{A})$ and $5 \%$ increments in $\mathrm{FEV}_{1} \%$ predicted $(\mathrm{B})$ are shown. Blue dots denote patients with abnormal RV:TLC by the upper limit of normal. RV, residual volume; TLC, total lung capacity.

which resulted in a relatively higher decline in $\mathrm{FEV}_{1}: \mathrm{FVC}$ compared with those with normal RV:TLC $(\mathrm{p}=0.001)$ (figure 5).

\section{Sensitivity analysis}

Overall, $41.4 \%$ of patients were obese (body mass index $>30$ ), 21.4\% had asthma diagnosis, $40.8 \%$ had reversibility $\left(\geq 12 \%\right.$ and $\geq 200 \mathrm{~mL}$ increase in $\mathrm{FEV}_{1}$ after bronchodilator administration), and FVC and $\mathrm{FEF}_{25-75}$ were lower than LLN in $4.1 \%$ and $1.2 \%$ of the patients, respectively. Sensitivity analyses with exclusion of patients with obesity, asthma, $\mathrm{FEV}_{1}$ reversibility, or FVC and $\mathrm{FEF}_{25-75}<\mathrm{LLN}$ did not change the observed associations. Additional sensitivity analyses with adjustment for Veterans Affairs Medical Center sites did not affect the findings.

Sensitivity analysis using the GOLD criteria to define COPD and determine those with preserved spirometry showed similar results (online supplementary appendix).

\section{DISCUSSION}

In this study of 7479 current and former smokers with preserved spirometry from the VHA, we found that (1) air trapping was prevalent, with approximately a third of patients at risk for COPD but with preserved spirometry having RV:TLC>ULN; (2) air trapping indices varied widely across the range of spirometric indices used for COPD definition $\left(\mathrm{FEV}_{1}\right.$ : $\mathrm{FVC}$ and $\left.\mathrm{FEV}_{1}\right)$; (3) patients with air trapping (RV:TLC $>\mathrm{ULN}$ ) were more likely to receive clinical diagnoses of COPD and to have higher all-cause mortality, and had increased healthcare utilisation and hospitalisation associated with COPD diagnosis; (4) in patients without overt air trapping (normal RV:TLC), those with high-normal RV:TLC had worse outcomes compared with their low-normal counterparts; and (5) patients with air trapping were more likely to progress to develop spirometric COPD. These findings indicate the predictive usefulness of lung volume measurements in those at risk for COPD, and argue for use of air trapping as an additional dimension for COPD definition and prognosis.

There is a major interest in the early detection of COPD for the purpose of prognostication and intervention. The traditional approach for diagnosis and management of COPD has been based on spirometry, although more recently respiratory symptoms have also been incorporated into the guidelines for treatment decision. Different perspectives exist regarding optimal criteria for spirometric diagnosis of COPD, as GOLD fixed ratio is recommended for its simplicity and consistency but may lead to an overdiagnosis of COPD, while LLN and Global Lung Initiative definitions adjust for variables like age, sex, height and ethnicity, but potentially introduce additional biases and may underdiagnose COPD. ${ }^{14}$ Regardless, COPD cohort studies have shown that smokers without spirometric COPD, by any of the above criteria, may indeed suffer from respiratory symptoms and acute exacerbation-like illnesses as those with spirometric COPD. ${ }^{4515}$ Furthermore, spirometric airflow indices usually used to define and rate the severity of COPD have not been found to be reliable predictors of future disease progression in these patients, and similarly their utility in prognostication of smokers with preserved spirometry remains unclear. ${ }^{16} 17$

Many studies have documented the significance of air trapping in patients with overt COPD and its association with increased morbidity and mortality. ${ }^{18-22}$ Others have shown that in mild disease or in smokers without GOLD-defined COPD, air trapping and hyperinflation may be associated with clinically important physiological impairment beyond the information provided by spirometry. ${ }^{15} 23$ Recently, in a study of individuals at risk for COPD due to heavy occupational exposure to secondhand tobacco smoke but with preserved spirometry, we showed RV:TLC to be negatively associated with exercise capacity, with the individuals who had RV:TLC values $\geq 90 \%$ predicted being half as likely to achieve their maximum predicted exercise capacity. ${ }^{2425}$ Our current study further uncovers the importance of lung volumes representing air trapping in predicting respiratory morbidity and progression to overt disease in smokers at risk for COPD but with preserved spirometry in a longitudinal manner. We found that in the presence of preserved spirometry, the smokers with air trapping (RV:TLC $>$ ULN) were more likely to have subsequent clinical diagnoses of COPD, a likely indicator of practitioners' consideration of patients' respiratory symptoms. Corroborating this finding was their higher rate of respiratory medication prescription and COPD-related healthcare utilisation compared with their counterparts without air trapping. Our study did not report specific cause of death in patients, but we were able to observe an increase in the number of COPD-related hospital and ICU admissions, which may suggest that at least some of the increased death was due to respiratory complications related to COPD. Nevertheless, air trapping, particularly if enhanced due to increased respiratory 


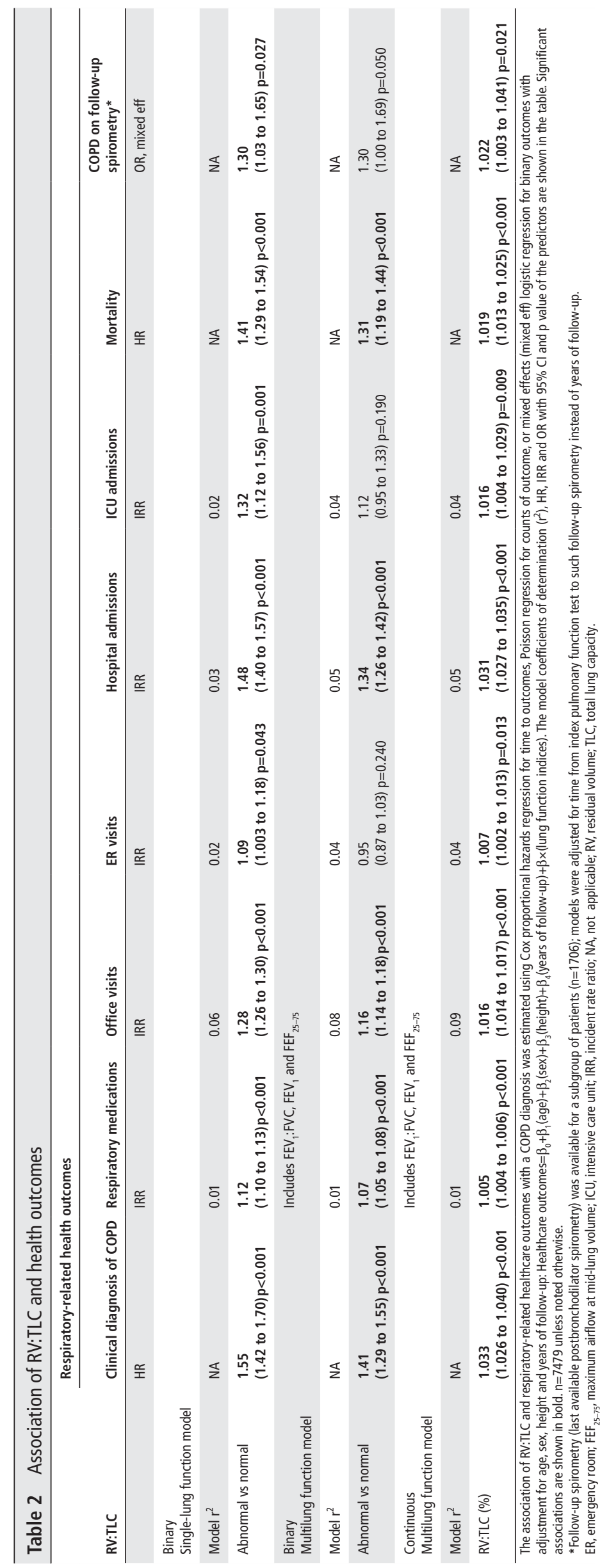




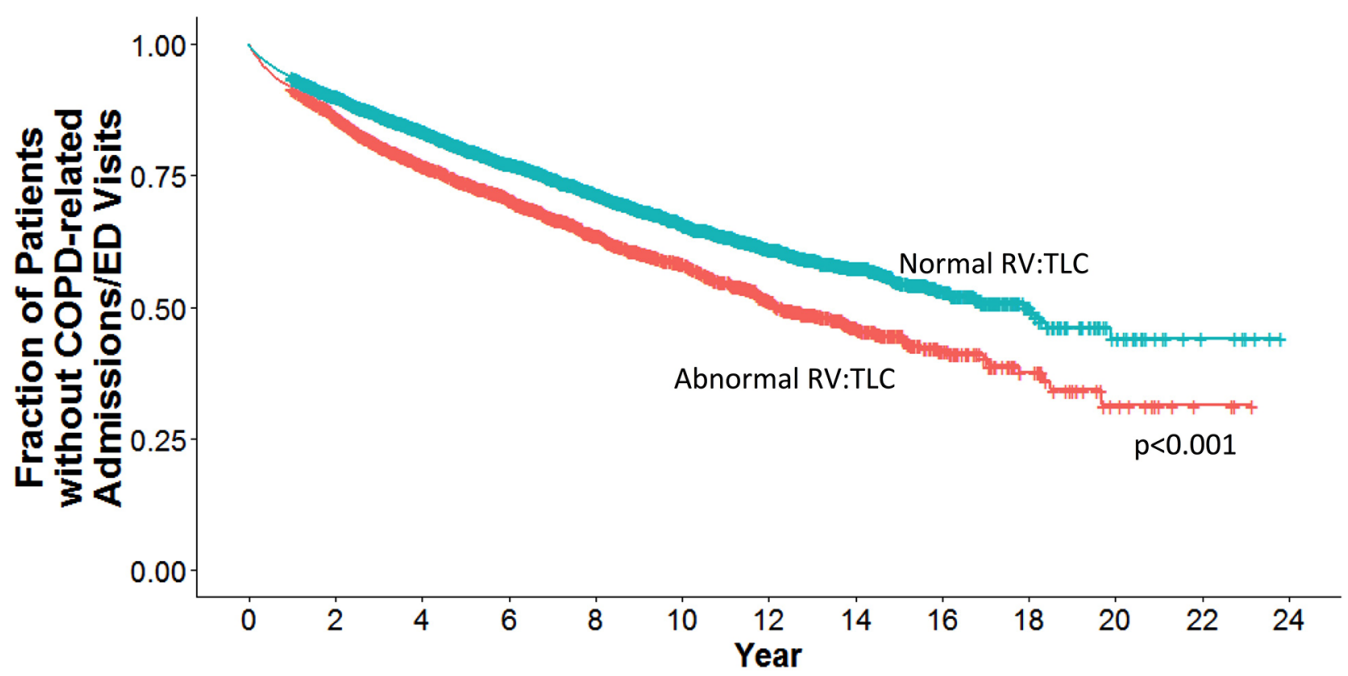

RV:TLC Number at Risk for COPD-related IIIness

\begin{tabular}{|c|c|c|c|c|c|c|c|c|c|c|c|c|c|}
\hline Abnormal & 2300 & 1810 & 1434 & 1141 & 841 & 610 & 394 & 203 & 87 & 32 & 11 & 3 & 0 \\
\hline \multirow[t]{2}{*}{ Normal } & 5179 & 4317 & 3511 & 2698 & 1972 & 1354 & 889 & 489 & 199 & 70 & 22 & 6 & 0 \\
\hline & 0 & 2 & 4 & 6 & 8 & 10 & $\begin{array}{c}12 \\
\text { Year }\end{array}$ & 14 & 16 & 18 & 20 & 22 & 24 \\
\hline
\end{tabular}

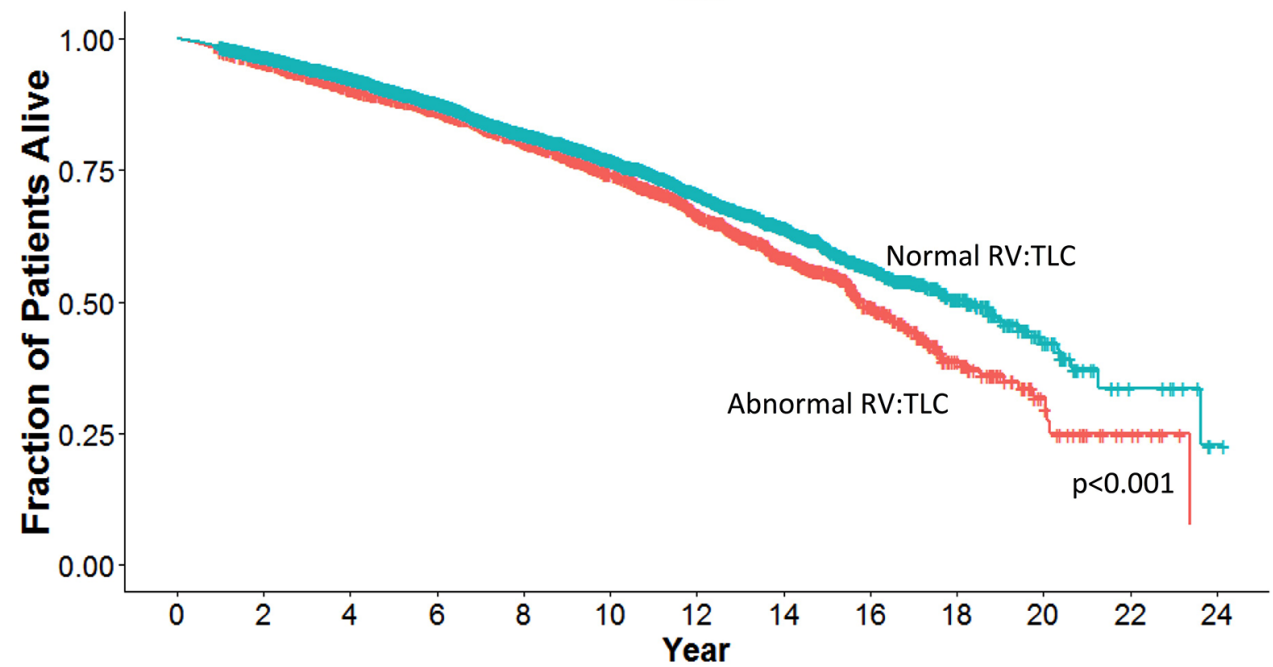

RV:TLC Number at Risk for Mortality

\begin{tabular}{|c|c|c|c|c|c|c|c|c|c|c|c|c|c|}
\hline Abnormal & $\begin{array}{l}2300 \\
5179\end{array}$ & $\begin{array}{l}2068 \\
4737\end{array}$ & $\begin{array}{l}1790 \\
4095\end{array}$ & $\begin{array}{l}1529 \\
3358\end{array}$ & $\begin{array}{l}1226 \\
2601\end{array}$ & $\begin{array}{c}942 \\
1902\end{array}$ & $\begin{array}{c}665 \\
1311\end{array}$ & $\begin{array}{l}379 \\
761\end{array}$ & $\begin{array}{l}172 \\
326\end{array}$ & $\begin{array}{c}62 \\
117\end{array}$ & $\begin{array}{l}23 \\
41\end{array}$ & $\begin{array}{l}7 \\
9\end{array}$ & $\begin{array}{l}0 \\
1\end{array}$ \\
\hline & 0 & 2 & 4 & 6 & 8 & 10 & $\begin{array}{c}12 \\
\text { Year }\end{array}$ & 14 & 16 & 18 & 20 & 22 & 24 \\
\hline
\end{tabular}

Figure 3 Survival curves for subjects dichotomised based on the upper limit of normal for RV:TLC. Survival curves represent survival rates with respect to time of follow-up among subjects with normal RV:TLC (blue) compared with those who had abnormal RV:TLC (red). Respiratory-related illness includes emergency room visits, hospital admissions and intensive care unit admissions. Abnormal RV:TLC: RV:TLC greater than the upper limit of normal; $p$ value: significance from comparisons in survival rates generated by adjusted (age, sex and height) Cox proportional hazards regression analysis. ED, emergency department; RV, residual volume; TLC, total lung capacity.

demands, may cause major shifts in intrathoracic pressures, and studies have shown that its consequences may extend beyond the lungs to other organ systems including cardiovascular function. ${ }^{26-29}$ Thus, identification of these patients at an early stage may aid in interventions related to pulmonary and cardiovascular and other systems complications. Overall, these findings demonstrate that measurement of lung volume that represents air trapping in those at risk for COPD could identify subgroups susceptible to health complications and disease progression.

There is currently no definitive recommendation for the use of one specific plethysmographic measurement in evaluating obstructive lung disease. RV:TLC has been widely adopted for its strong association with degree of airflow obstruction in COPD. ${ }^{30} 31$ While this association was weaker in our cohort of smokers with preserved spirometry and no airflow obstruction, RV:TLC remained predictive of morbidity and mortality. RV:TLC is thought to be sensitive in detecting small changes in lung volume, ${ }^{32}$ and increases in RV are reported to be the earliest functional abnormality observed in heavy smokers with chronic bronchitis. ${ }^{33}$ Corbin et $a l^{34}$ showed increases in RV and, to a lesser extent, TLC over a 4-year follow-up in smokers despite stable $\mathrm{FEV}_{1}: \mathrm{FVC}$ measurements. Other measures of air trapping 

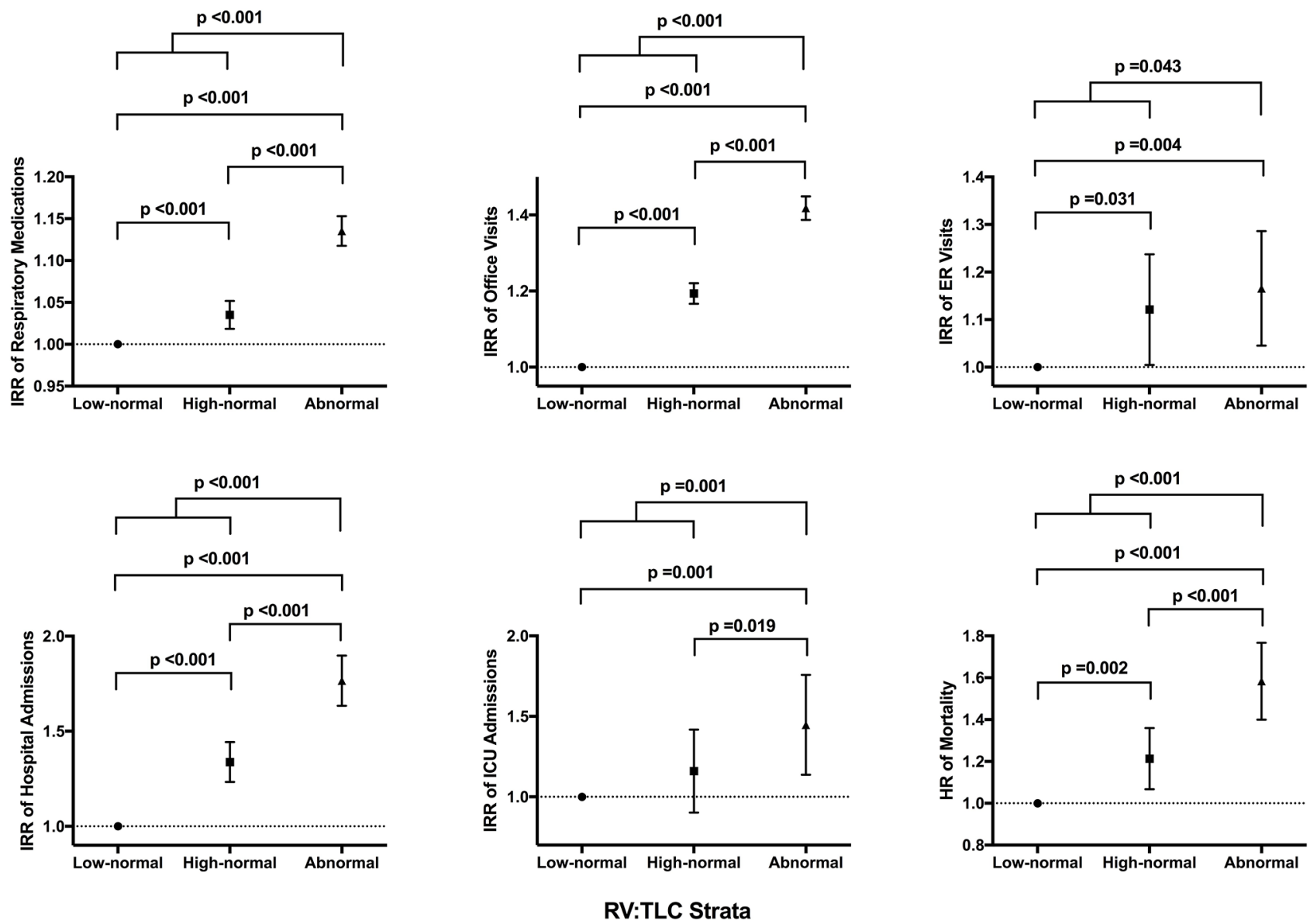

Figure 4 Associations of healthcare outcomes with RV:TLC strata. Graphs represent incident rate ratio (IRR) and hazard ratio (HR) with 95\% Cls from Poisson and Cox proportional hazard regression analyses, respectively, of the association between healthcare outcomes and RV:TLC strata

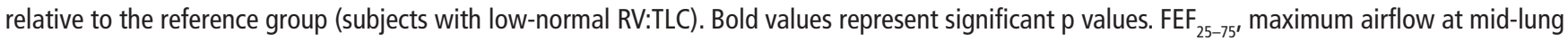
volume; RV, residual volume; TLC, total lung capacity.

and static hyperinflation including FRC, IC, and their ratios to TLC and their predictive values have also been studied in COPD. Casanova and colleagues ${ }^{35}$ reported an increase in respiratory and overall mortality in patients with COPD when IC:TLC fell below $25 \%$. In our study of smokers with preserved spirometry, the prevalence of abnormal FRC, IC, FRC:TLC or IC:TLC was substantially smaller than that for abnormal RV:TLC. Nevertheless, these indices were all associated with adverse health outcomes.

It is intriguing that smokers with preserved spirometry have such a wide distribution of RV:TLC over airflow indices particularly as air trapping is usually considered to be a consequence of airflow obstruction. However, destruction of lung tissue, as it could occur with smoking, may also contribute to the development of air trapping through loss of lung elastance, untethering of small airways, and subsequent increase in closing volume and air trapping. ${ }^{36}$ A notable finding in our study is that the abnormally high RV:TLC was mostly achieved by a substantial increase in the volume of RV rather than any decrease in the volume of TLC, and in fact TLC was mildly elevated in those with abnormal RV:TLC compared with those with normal RV:TLC. This finding too implicates loss of lung elastance along with the outward pull on the lungs by the chest wall as the contributing mechanism at this early stage of the disease. Interestingly, during the follow-up period available in our study, the higher rate of progression to spirometric COPD among those with abnormal RV:TLC seems to have been the result of a relative increase in
FVC, rather than any decrease in $\mathrm{FEV}_{1}$, possibly implicating compensatory expansion of the chest cavity and increase in TLC as the responsible mechanism as explained below. Radiographic studies have shown air trapping to be a regional process with patchy areas of involved and uninvolved lung, ${ }^{37}$ which suggests that areas with lung tissue loss with resulting air trapping and untethered small airways may indeed be present adjacent to areas of relatively normal lung without air trapping and with normal airways. Given the regional nature of this process, the increase in TLC may then cause outward pull on at least the small airways within normal areas of the lungs, increasing their diameters, with the result that the overall airflow through all small airways throughout the lungs may be unaffected at this early stage of the disease. This of course would be a hypothesis that would need further evaluation and testing.

Our study has several limitations. First, our investigation was a retrospective review of EHR, making it vulnerable to misclassification bias and confounding, including reliance on proxies to ascertain health outcomes such as COPD diagnosis codes to assess respiratory symptoms, or the number of respiratory medication prescriptions to assess need for medication. Such proxies have been widely used to ascertain symptoms from EHR and are neutral to biases towards having air trapping, and thus should not have affected the corresponding analyses. Second, while smoking status was obtained using diagnosis codes of smoking, information regarding length and amount of smoking was lacking. Our approach was based on the assumptions that almost all smokers 


\section{Chronic obstructive pulmonary disease}

Table 3 Characteristics of subjects who had follow-up spirometry

\begin{tabular}{|c|c|c|c|c|c|}
\hline Characteristics & All patients with follow-up spirometry & Patients with normal RV:TLC & Patients with abnormal RV:TLC & Difference $(95 \% \mathrm{Cl})$ & $P$ values \\
\hline \multicolumn{6}{|l|}{ Demographics } \\
\hline $\mathrm{n}$ (\% of the study cohort) & $1706(22.8)$ & $1124(21.7)$ & $582(25.3)$ & $-3.6 \%(-5.7$ to 1.5$)$ & $<0.001$ \\
\hline Age (years) & $61.3 \pm 10.4$ & $60.9 \pm 10.3$ & $62.1 \pm 10.6$ & $-1.2(-2.2$ to 0.2$)$ & 0.023 \\
\hline Sex (female), n (\%) & $123(7.2)$ & $109(9.7)$ & $14(2.4)$ & $7.3 \%(5.2$ to 9.4$)$ & $<0.001$ \\
\hline Height $(\mathrm{cm})$ & $174.7 \pm 7.8$ & $175.0 \pm 7.9$ & $173.9 \pm 7.7$ & $1.1(0.3$ to 1.9$)$ & 0.006 \\
\hline BMI $\left(\mathrm{kg} / \mathrm{m}^{2}\right)$ & $29.7 \pm 5.6$ & $29.7 \pm 5.6$ & $29.6 \pm 5.7$ & $0.004(-0.6$ to 0.6$)$ & 0.989 \\
\hline Years of follow-up & $10.3 \pm 4.6$ & $10.0 \pm 4.6$ & $10.8 \pm 4.6$ & $-0.8(-1.3$ to 0.3$)$ & $<0.001$ \\
\hline \multicolumn{6}{|l|}{ Baseline airflow indices } \\
\hline $\mathrm{FEV}_{1}(\mathrm{~L})$ & $3.07 \pm 0.58$ & $3.15 \pm 0.60$ & $2.93 \pm 0.52$ & $0.22(0.16$ to 0.28$)$ & $<0.001$ \\
\hline $\mathrm{FEV}_{1}(\%$ predicted $)$ & $88 \pm 9$ & $90 \pm 10$ & $84 \pm 8$ & $5.7(4.8$ to 6.6$)$ & $<0.001$ \\
\hline FVC (L) & $4.00 \pm 0.76$ & $4.09 \pm 0.78$ & $3.82 \pm 0.68$ & $0.27(0.20$ to 0.34$)$ & $<0.001$ \\
\hline FVC (\% predicted) & $89 \pm 10$ & $91 \pm 11$ & $86 \pm 9$ & 5.4 (4.4 to 6.4$)$ & $<0.001$ \\
\hline $\mathrm{FEV}_{1}$ :FVC (\%) & $77.0 \pm 4.8$ & $77.1 \pm 4.9$ & $76.7 \pm 4.6$ & $0.4(-0.1$ to 0.9$)$ & 0.093 \\
\hline $\mathrm{FEV}_{1}: \mathrm{FVC}$ (\% predicted) & $98.3 \pm 5.8$ & $98.5 \pm 5.8$ & $97.9 \pm 5.7$ & $0.58(0.004$ to 1.16$)$ & 0.048 \\
\hline $\mathrm{FEF}_{25-75}(\mathrm{~L})$ & $2.85 \pm 0.94$ & $2.92 \pm 0.97$ & $2.73 \pm 0.85$ & $0.19(0.10$ to 0.28$)$ & $<0.001$ \\
\hline $\mathrm{FEF}_{25-75}(\%$ predicted $)$ & $86 \pm 24$ & $87 \pm 25$ & $82 \pm 21$ & 5.4 (3.1 to 7.8$)$ & $<0.001$ \\
\hline Reversibility in $\mathrm{FEV}_{1}(\mathrm{~mL})$ & $187 \pm 207$ & $173 \pm 198$ & $216 \pm 220$ & $-43(-64$ to 22$)$ & $<0.001$ \\
\hline Reversibility in $\mathrm{FEV}_{1}(\%)$ & $7 \pm 9$ & $6 \pm 8$ & $9 \pm 11$ & $-2.5(-3.5$ to 1.6$)$ & $<0.001$ \\
\hline Reversibility in $\mathrm{FEV}_{1}, \mathrm{n}(\%)$ & 709 (41.6) & $435(38.7)$ & $274(47.1)$ & $-8.4 \%$ (-13.3 to 3.4$)$ & $<0.001$ \\
\hline \multicolumn{6}{|l|}{ Lung volume indices } \\
\hline $\operatorname{TLC}(\mathrm{L})$ & $6.67 \pm 1.09$ & $6.44 \pm 1.01$ & $7.12 \pm 1.10$ & $-0.68(-0.78$ to 0.57$)$ & $<0.001$ \\
\hline TLC (\% predicted) & $100 \pm 12$ & $96 \pm 10$ & $107 \pm 13$ & $-10.5(-11.7$ to 9.4$)$ & $<0.001$ \\
\hline $\mathrm{RV}(\mathrm{L})$ & $2.67 \pm 0.77$ & $2.30 \pm 0.50$ & $3.39 \pm 0.69$ & $-1.09(-1.14$ to 1.03$)$ & $<0.001$ \\
\hline RV (\% predicted) & $121 \pm 33$ & $104 \pm 20$ & $154 \pm 29$ & $-50(-52$ to 48$)$ & $<0.001$ \\
\hline FRC (L) & $3.57 \pm 0.86$ & $3.33 \pm 0.74$ & $4.07 \pm 0.86$ & $-0.74(-0.83$ to 0.66$)$ & $<0.001$ \\
\hline FRC (\% predicted) & $103 \pm 23$ & $95 \pm 19$ & $118 \pm 23$ & -22 ( -24 to 20$)$ & $<0.001$ \\
\hline IC (L) & $3.10 \pm 0.71$ & $3.12 \pm 0.71$ & $3.06 \pm 0.69$ & $0.06(-0.02$ to 0.14$)$ & 0.121 \\
\hline IC (\% predicted) & $74 \pm 14$ & $94 \pm 14$ & $73 \pm 14$ & $1.3(-0.2$ to 2.8$)$ & 0.089 \\
\hline RV:TLC (\%) & $40 \pm 8$ & $36 \pm 6$ & $48 \pm 5$ & $-11.7(-12.3$ to 11.2$)$ & $<0.001$ \\
\hline RV:TLC (\% predicted) & $119 \pm 22$ & $107 \pm 14$ & $143 \pm 14$ & $-36(-37$ to 34$)$ & $<0.001$ \\
\hline FRC:TLC (\%) & $53 \pm 9$ & $52 \pm 8$ & $57 \pm 8$ & -5 (-6 to 4$)$ & $<0.001$ \\
\hline FRC:TLC (\% predicted) & $95 \pm 15$ & $92 \pm 14$ & $101 \pm 13$ & $-9(-10$ to 7$)$ & $<0.001$ \\
\hline IC:TLC (\%) & $47 \pm 8$ & $48 \pm 8$ & $43 \pm 7$ & 5.4 (4.5 to 6.2$)$ & $<0.001$ \\
\hline IC:TLC (\% predicted) & $93 \pm 20$ & $96 \pm 19$ & $86 \pm 19$ & 10 (8 to 12 ) & $<0.001$ \\
\hline \multicolumn{6}{|l|}{ Follow-up spirometry* } \\
\hline $\begin{array}{l}\text { Age at follow-up spirometry } \\
\text { (years) }\end{array}$ & $65.4 \pm 10.4$ & $64.7 \pm 10.3$ & $66.7 \pm 10.4$ & $-2.0(-3.0$ to 1.0$)$ & $<0.001$ \\
\hline $\begin{array}{l}\text { Height at follow-up spirometry } \\
(\mathrm{cm})\end{array}$ & $174.5 \pm 8.0$ & $174.9 \pm 8.1$ & $173.8 \pm 7.8$ & $1.1(0.3$ to 1.9$)$ & 0.007 \\
\hline $\begin{array}{l}\text { Time from index PFT to follow-up } \\
\text { spirometry (years) }\end{array}$ & $4.1 \pm 3.1$ & $3.8 \pm 2.9$ & $4.6 \pm 3.3$ & $-0.8(-1.1$ to 0.5$)$ & $<0.001$ \\
\hline $\mathrm{FEV}_{1}(\mathrm{~L})$ & $2.69 \pm 0.65$ & $2.77 \pm 0.65$ & $2.53 \pm 0.62$ & $0.25(0.18$ to 0.31$)$ & $<0.001$ \\
\hline $\mathrm{FEV}_{1}(\%$ predicted $)$ & $79 \pm 15$ & $81 \pm 15$ & $75 \pm 14$ & 6.5 (5.0 to 7.9$)$ & $<0.001$ \\
\hline FVC (L) & $3.67 \pm 0.84$ & $3.75 \pm 0.86$ & $3.51 \pm 0.80$ & 0.25 (0.16 to 0.33$)$ & $<0.001$ \\
\hline FVC (\% predicted) & $84 \pm 15$ & $86 \pm 15$ & $81 \pm 14$ & 4.8 (3.3 to 6.3 ) & $<0.001$ \\
\hline $\mathrm{FEV}_{1}: \mathrm{FVC}(\%)$ & $74 \pm 8$ & $74 \pm 8$ & $72 \pm 8$ & 2.0 (1.2 to 2.8$)$ & $<0.001$ \\
\hline $\mathrm{FEV}_{1}: \mathrm{FVC}(\%$ predicted) & $95 \pm 10$ & $95 \pm 10$ & $93 \pm 10$ & 2.5 (1.5 to 3.5$)$ & $<0.001$ \\
\hline $\mathrm{FEF}_{25-75}(\mathrm{~L})$ & $2.26 \pm 0.98$ & $2.38 \pm 1.00$ & $2.04 \pm 0.88$ & 0.34 (0.24 to 0.43$)$ & $<0.001$ \\
\hline $\mathrm{FEF}_{25-75}(\%$ predicted $)$ & $72 \pm 29$ & $75 \pm 29$ & $65 \pm 25$ & $10.0(7.2$ to 12.8$)$ & $<0.001$ \\
\hline
\end{tabular}


Table 3 Continued

\begin{tabular}{|c|c|c|c|c|c|}
\hline Characteristics & All patients with follow-up spirometry & Patients with normal RV:TLC & Patients with abnormal RV:TLC & Difference $(95 \% \mathrm{Cl})$ & $P$ values \\
\hline \multirow{2}{*}{\multicolumn{6}{|c|}{$\begin{array}{l}\text { P-values for significant comparisons are shown in bold. } \\
\text { Demographics and lung function in patients with preserved spirometry. Patients were stratified according to abnormal and normal RV:TLC by the upper limit of normal. Data are presented as mean } \pm \text { SD or number of } \\
\text { patients with positive value for the variable }(n) \text { out of the total number of patients }(\mathrm{N}) \text { and percentage of patients }(\%) \text { and difference }(95 \% \mathrm{Cl}) \text { with } \mathrm{p} \text { value for unadjusted comparison between normal and abnormal } \\
\text { RV:TLC. }\end{array}$}} \\
\hline & & & & & \\
\hline \multicolumn{6}{|c|}{$\begin{array}{l}\text { *Follow-up spirometry (last available postbronchodilator spirometry) was available for a subgroup of patients. Reference equations: Measures of pulmonary function and \% predicted of normal values were calculated } \\
\text { using Crapo predicted formulas (Crapo et al, } 1981 \text { and 1982), except for FRC:TLC, IC and IC:TLC. Quanjer predicted formulas were used for FRC:TLC and IC (Quanjer et al, 1993), and Francisco predicted formulas were } \\
\text { used for IC:TLC (Francisco et al, 2009). Reversibility defined as } \geq 12 \% \text { and } \geq 200 \mathrm{~mL} \text { increase in FEV, after bronchodilator administration. }\end{array}$} \\
\hline
\end{tabular}

begin smoking before age 18 , and it is likely that the veterans in this cohort with documented 'former' or 'current' smoking status after age 40 likely had a substantial smoking history before smoking diagnosis code was entered in their EHR. ${ }^{38} 39$ Third, the reasons that the patients were referred for spirometry and plethysmography testing are unclear. Although it is possible that the patients were referred for a variety of reasons including routine preoperative work-up, it is likely that the majority of patients were referred out of concerns for respiratory symptoms. Similarly,
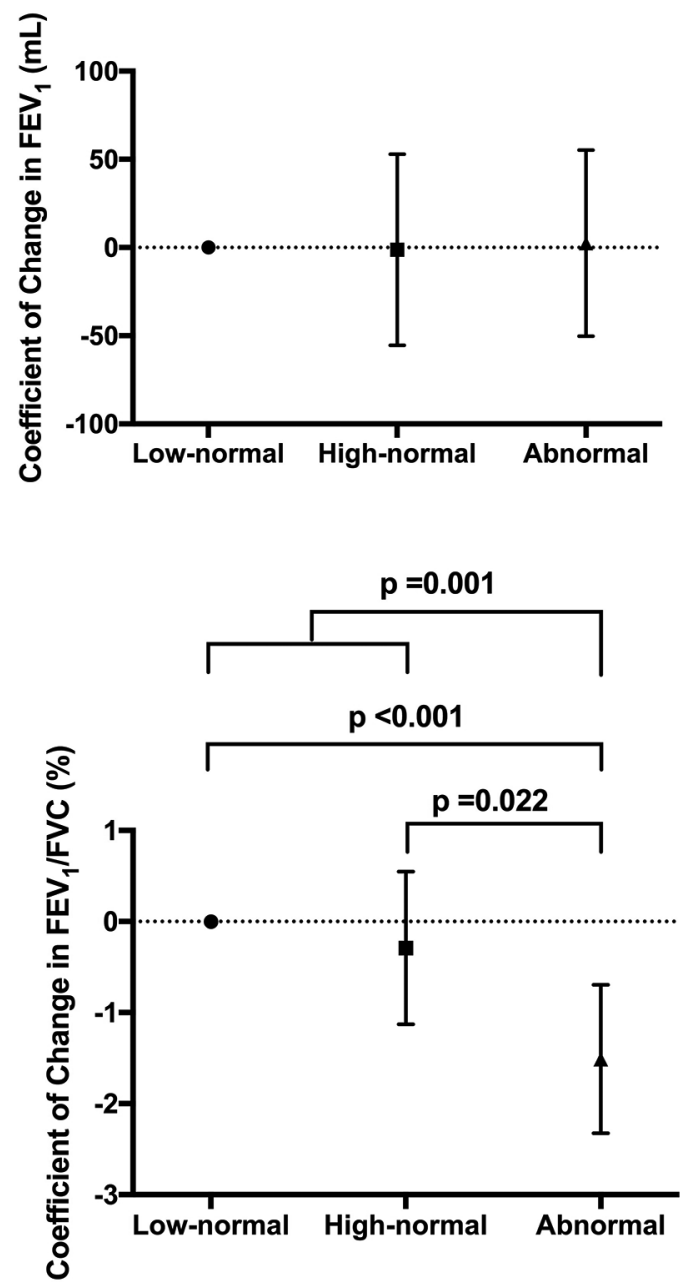

the reasons that patients were referred for repeat spirometry are unclear. However, it is possible that only those patients with persistent or worsening symptoms underwent follow-up spirometry. Thus, the findings of this study may be mostly generalisable to those smokers at risk for COPD who have some degree of respiratory symptoms. Although we are unaware of any harmonisation of PFT equipment or protocols across the VHA medical centres, it is known that most Veterans Affairs Medical Centers have been closely associated with medical schools and academic
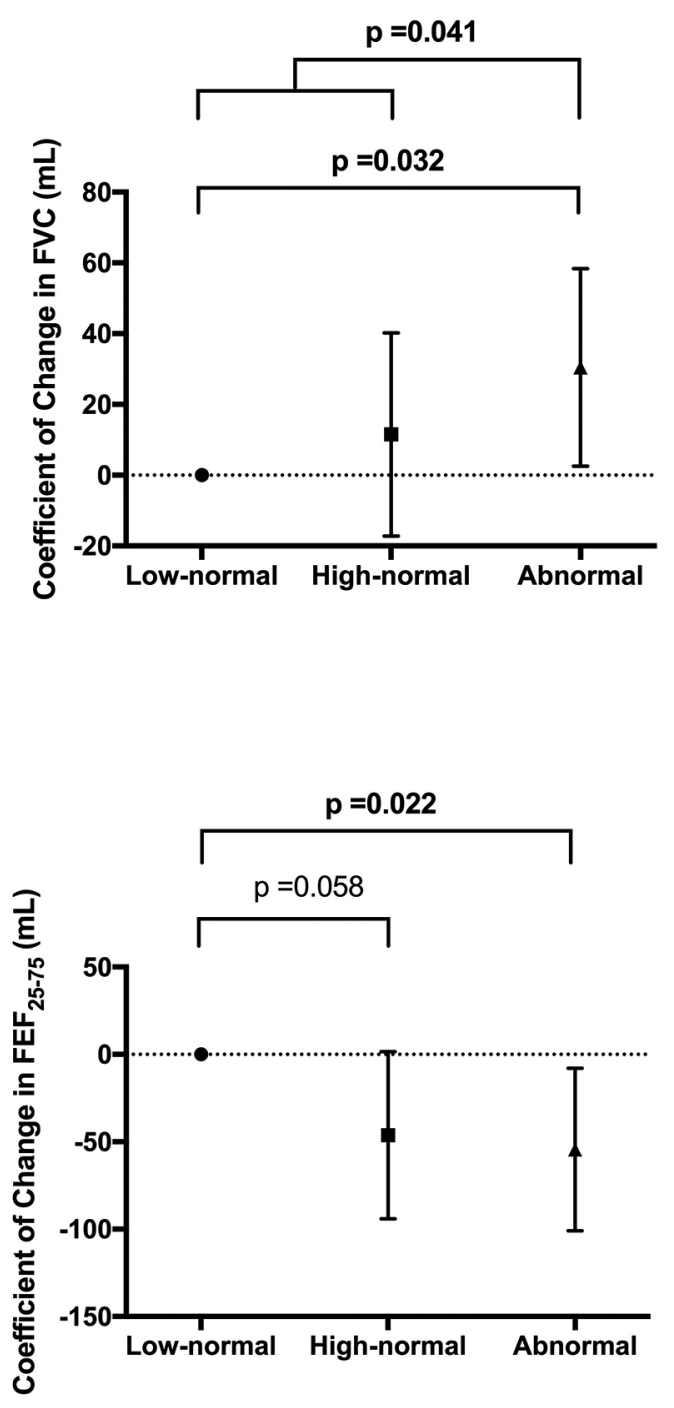

\section{RV:TLC Strata}

Figure 5 Comparison of change in airflow indices on follow-up spirometry across the RV:TLC strata. Graphs represent coefficient of change with 95\% Cls in airflow indices across the RV:TLC strata relative to the reference group (subjects with low-normal RV:TLC) from mixed effect linear regression modelling with adjustment for age, sex, height and time to follow-up spirometry. Bold values represent significant $\mathrm{p}$ values. $\mathrm{FEF}_{25-}$ ${ }_{75^{\prime}}$ maximum airflow at mid-lung volume; RV, residual volume; TLC, total lung capacity. 
medical centres for decades, ${ }^{40}$ and thus it is likely that their PFT measurements were done at comparable qualities with those done at non-VHA major academic medical centres. Furthermore, the proportion of patients with abnormal RV:TLC within the VHA medical centres generally followed a normal distribution (online supplementary appendix), discrediting the assumption of any site-specific measurement bias. Finally, our study design algorithm aimed to optimise the maximum number of patients at risk for COPD but with preserved spirometry while at the same time excluding those with non-relevant diseases including restrictive lung disease. Through this approach, patients with certain diseases and characteristics (such as asthma and obesity) were included, which may have confounded our analyses. However, sensitivity analysis with exclusion of the patients with concerns for confounding did not significantly change our findings.

In conclusion, in this study based on the nationwide Veterans Affairs EHR, air trapping was common in smokers with preserved spirometry and predicted adverse respiratory outcomes and progression to overt COPD. Further prospective validation of this retrospective study could increase confidence in the usefulness of air trapping as a predictor for morbidity and disease progression in smokers without overt COPD. Moreover, understanding the underlying biological mechanisms involved in the development of air trapping in the absence of airflow obstruction could lead to discovery of novel therapeutic strategies.

Acknowledgements The authors would like to thank the Veterans Administration Informatics and Computing Infrastructure (VINCI) concierge, Mr Sundaragandhi P Radhakrishnan and Mr James M Potter for their assistance with implementation of algorithm and data extraction from VINCl, and Drs Paul D Blanc and Warren M Gold for their helpful discussion during the preparation of the manuscript.

Contributors MA conceived and designed the study. MA, BB and $S Z$ developed the study protocols. SZ, BB, BG, JJ and MA collected the data. SZ, MA, AT, BB and JJ analysed and interpreted the data. MA, AT, SZ, BB and JJ prepared the manuscript. $\mathrm{MA}$ and $\mathrm{BB}$ obtained funding.

Funding This work was supported by the Flight Attendant Medical Research Institute (MA) and Radboud University School of Medicine Scholarship (BB).

Competing interests None declared.

Patient consent Not required.

Ethics approval The University of California San Francisco Institutional Review Board and the Veterans Health Administration Research and Development Committee approved this study.

Provenance and peer review Not commissioned; externally peer reviewed.

\section{REFERENCES}

1 Vogelmeier CF, Criner GJ, Martinez FJ, et al. Global Strategy for the Diagnosis, Management and Prevention of Chronic Obstructive Lung Disease 2017 Report: GOLD Executive Summary. Respirology 2017;22:575-601.

2 Quanjer PH, Tammeling GJ, Cotes JE, et al. Lung volumes and forced ventilatory flows. Report Working Party Standardization of Lung Function Tests, European Community for Steel and Coal. Official Statement of the European Respiratory Society. Eur Respir J Supp/ 1993;16:5-40.

3 Lung function testing: selection of reference values and interpretative strategies. American Thoracic Society. Am Rev Respir Dis 1991;144:1202-18.

4 Woodruff PG, Barr RG, Bleecker E, et al. Clinical Significance of Symptoms in Smokers with Preserved Pulmonary Function. N Engl J Med 2016;374:1811-21.

5 Bowler RP, Kim V, Regan E, et al. Prediction of acute respiratory disease in current and former smokers with and without COPD. Chest 2014;146:941-50.

6 Regan EA, Lynch DA, Curran-Everett D, et al. Clinical and Radiologic Disease in Smokers With Normal Spirometry. JAMA Intern Med 2015;175:1539-49.

7 Martinez CH, Murray S, Barr RG, et al. Respiratory Symptoms Items from the COPD Assessment Test Identify Ever-Smokers with Preserved Lung Function at Higher Risk for Poor Respiratory Outcomes. An Analysis of the Subpopulations and Intermediate Outcome Measures in COPD Study Cohort. Ann Am Thorac Soc 2017;14:636-42.

8 Langer D, Ciavaglia CE, Neder JA, et al. Lung hyperinflation in chronic obstructive pulmonary disease: mechanisms, clinical implications and treatment. Expert Rev Respir Med 2014:8:731-49.

9 Thomas M, Decramer M, O'Donnell DE. No room to breathe: the importance of lung hyperinflation in COPD. Prim Care Respir J 2013;22:101-11.
10 Crapo RO, Casaburi R, Coates AL, et al. Guidelines for methacholine and exercise challenge testing-1999. This official statement of the American Thoracic Society was adopted by the ATS Board of Directors, July 1999. Am J Respir Crit Care Med 2000;161:309-29.

11 Crapo RO, Morris AH, Gardner RM. Reference spirometric values using techniques and equipment that meet ATS recommendations. Am Rev Respir Dis 1981;123:659-64.

12 Crapo RO, Morris AH, Gardner RM. Reference values for pulmonary tissue volume, membrane diffusing capacity, and pulmonary capillary blood volume. Bull Eur Physiopathol Respir 1982;18:893-9.

13 Francisco LM, Salinas VH, Brown KE, et al. PD-L1 regulates the development, maintenance, and function of induced regulatory T cells. J Exp Med 2009;206:3015-29.

14 Guder G, Brenner S, Angermann CE, et al. "GOLD or lower limit of normal definition? A comparison with expert-based diagnosis of chronic obstructive pulmonary disease in a prospective cohort-study". Respir Res 2012:13(1):13.

15 Elbehairy AF, Guenette JA, Faisal A, et al. Mechanisms of exertional dyspnoea in symptomatic smokers without COPD. Eur Respir J 2016;48:694-705.

16 Vestbo J, Lange P. Can GOLD Stage 0 provide information of prognostic value in chronic obstructive pulmonary disease? Am J Respir Crit Care Med 2002;166:329-32.

17 Strassmann A, Frei A, Haile SR, et al. Commonly Used Patient-Reported Outcomes Do Not Improve Prediction of COPD Exacerbations: A Multicenter 4 $\frac{1}{2}$ Year Prospective Cohort Study. Chest 2017;152.

18 Marin JM, Carrizo SJ, Gascon M, et al. Inspiratory capacity, dynamic hyperinflation, breathlessness, and exercise performance during the 6-minute-walk test in chronic obstructive pulmonary disease. Am J Respir Crit Care Med 2001;163:1395-9.

19 Waschki B, Kirsten A, Holz O, et al. Physical activity is the strongest predictor of all-cause mortality in patients with COPD: a prospective cohort study. Chest 2011;140:331-42.

20 Casanova C, Cote C, de Torres JP, et al. Inspiratory-to-Total Lung Capacity Ratio Predicts Mortality in Patients with Chronic Obstructive Pulmonary Disease. Am J Respir Crit Care Med 2005;171:591-7.

21 Callens E, Graba S, Gillet-Juvin K, et al. Measurement of dynamic hyperinflation after a 6-minute walk test in patients with COPD. Chest 2009;136:1466-72.

22 Garcia-Rio F, Lores V, Mediano 0, et al. Daily physical activity in patients with chronic obstructive pulmonary disease is mainly associated with dynamic hyperinflation. Am J Respir Crit Care Med 2009;180:506-12.

23 O'Donnell DE, Laveneziana P, Webb K, et al. Chronic obstructive pulmonary disease: clinical integrative physiology. Clin Chest Med 2014;35:51-69.

24 Arjomandi M, Zeng S, Blanc PD, et al. Increasing the Resolution of Chronic Obstructive Pulmonary Disease Definition. Lessons from a Cohort with Remote but Extensive Exposure to Secondhand Tobacco Smoke. Ann Am Thorac Soc 2018;15 S122-S123.

25 Arjomandi M, Zeng S, Geerts J, et al. Lung volumes identify an at-risk group in persons with prolonged secondhand tobacco smoke exposure but without overt airflow obstruction. BMJ Open Respir Res 2018;5:e000284.

26 Martinez $\mathrm{CH}$, Kim V, Chen Y, et al. The clinical impact of non-obstructive chronic bronchitis in current and former smokers. Respir Med 2014;108:491-9.

27 Poor HD, Kawut SM, Liu CY, et al. Pulmonary hyperinflation due to gas trapping and pulmonary artery size: The MESA COPD Study. PLoS One 2017;12:e0176812.

28 Smith BM, Kawut SM, Bluemke DA, et al. Pulmonary hyperinflation and left ventricular mass: the Multi-Ethnic Study of Atherosclerosis COPD Study. Circulation 2013;127:1503-11.

29 Watz H, Waschki B, Meyer T, et al. Decreasing cardiac chamber sizes and associated heart dysfunction in COPD: role of hyperinflation. Chest 2010;138:32-8

30 Dykstra BJ, Scanlon PD, Kester MM, et al. Lung volumes in 4,774 patients with obstructive lung disease. Chest 1999:115:68-74.

31 Ruppel GL. What is the clinical value of lung volumes? Respir Care 2012;57 26-38.

32 Deesomchok A, Webb KA, Forkert L, et al. Lung hyperinflation and its reversibility in patients with airway obstruction of varying severity. COPD 2010;7:428-37.

33 Bates DV, Woolf CR, Paul GI. A report on the first two stages of the co-ordinated study of chronic bronchitis in the Department of Veterans Affairs, Canada. Med Serv J Can 1962;18:211-303.

34 Corbin RP, Loveland M, Martin RR, et al. A four-year follow-up study of lung mechanics in smokers. Am Rev Respir Dis 1979;120:293-304.

35 Casanova C, Cote C, de Torres JP, et al. Inspiratory-to-total lung capacity ratio predicts mortality in patients with chronic obstructive pulmonary disease. Am J Respir Crit Care Med 2005;171:591-7.

36 Gagnon P, Guenette JA, Langer D, et al. Pathogenesis of hyperinflation in chronic obstructive pulmonary disease. Int J Chron Obstruct Pulmon Dis 2014;9:187-201.

37 Mets OM, de Jong PA, van Ginneken B, et al. CT air trapping is independently associated with lung function reduction over time. PLoS One 2013:8:e61783.

38 Services USDoHaH. The Health Consequences of Smoking- 50 Years of Progress. Atlanta: U.S: Department of Health and Human Services, Centers for Disease Control and Prevention, National Center for Chronic Disease Prevention and Health Promotion, Office on Smoking and Health, 2014.

39 IoMUCoSCiMaV P, Bondurant SWR, eds. Combating Tobacco Use in Military and Veteran Populations. Washington (DC: National Academies Press (US), 2009.

40 Hollingsworth JW, Bondy PK. The role of Veterans Affairs hospitals in the health care system. N Engl J Med 1990;322:1851-7. 